\title{
Wounds and words: A lexical and syntactic analysis of Casocot's “There are other things beside brightness and light"
}

\author{
Veronico N. Tarrayo \\ Department of English, Faculty of Arts and Letters, University of Santo Tomas, España Boulevard, Sampaloc, \\ Manila, the Philippines
}

\begin{abstract}
While there has been a sustained interest in conducting stylistic studies on fiction, specifically novels and short stories, the literature about stylistic analysis of flash fiction as a literary genre remains scant. Thus, the present study attempts to conduct a lexical and syntactic analysis of Ian Rosales Casocot's "There Are Other Things Beside Brightness and Light." The analysis was anchored in two of the four linguistic and stylistic categories proposed by Leech and Short (2007), namely lexical and grammatical. To communicate the narrator's traumatic experience, the following lexical categories were found: words that evoke the main character's recollected sensations, particularly visual; a Latin expression, and slang words; concrete nouns providing access to the feelings of the main character; abstract nouns connoting psychological or emotional processes; and adjectives depicting sensory imageries and representing, along with some verbs, psychological states that carry negative connotations. Stative verbs vis-à-vis dynamic ones echo the impressions of attachment and detachment, and memory in the story, which link to the adverbs of manner in the text. On the other hand, these grammatical features contributed to text interpretation: cumulative or loose sentences depicting a series of rapid thoughts of the narrator who recalls a traumatic experience; mini-paragraphs, i.e., text fragmentation, foregrounding the theme of the narrative; verb-tense shift from past to future, and the demonstrative pronouns that and this representing the struggle of the narrator to escape from the vexatious memory of pain and trauma; and the em dash paving the way for the narrator's emotional rumination. The stylistic analysis, particularly lexical and syntactic, provides a more objective and profound understanding of the underlying meanings of the FF under study.
\end{abstract}

Keywords: Flash fiction; Philippine literature; stylistic analysis

\begin{tabular}{|c|c|c|}
\hline $\begin{array}{l}\text { First Received: } \\
1 \text { April } 2020 \\
\text { Final Proof Received: } \\
25 \text { September } 2020\end{array}$ & $\begin{array}{c}\text { Revised: } \\
\text { 19 July } 2020\end{array}$ & $\begin{array}{c}\text { Accepted: } \\
\text { 4 August 2020 } \\
\text { Published: } \\
\text { 30 September 2020 }\end{array}$ \\
\hline $\begin{array}{l}\text { How to cite (in APA style): } \\
\text { Tarrayo, V.N. (2020). Wounds an } \\
\text { are other things beside brigh } \\
\text { 10(2), 502-512. https://doi.ol }\end{array}$ & $\begin{array}{l}\text { A lexical al } \\
\text { d light”. In } \\
\text { 09/ijal.v10 }\end{array}$ & $\begin{array}{l}\text { actic analysis of Casocot's "There } \\
\text { n Journal of Applied Linguistics, } \\
4\end{array}$ \\
\hline
\end{tabular}

\section{INTRODUCTION}

Working with language involves attention to meaning-making devices utilized and the ways through which a text is conveyed to the receiver. In fiction, for instance, writers employ certain linguistic and literary devices in order to convey their desired communicative goal, and depending on the purpose of their communication, they choose such devices consciously or unconsciously. In fact, Leech and Short (2007) aver:
... the great novelists of the English language have been, arguably without exception, also great artists in the use of words, and the challenge remains of trying to explain the nature of that artistry, and how it integrates with the larger artistic achievement of the writer. (p. 2)

Further, language serves as the essential tool that fiction writers use for literary creativity. It is through the literary language that literature delights

\footnotetext{
* Corresponding Author

Email: vntarrayo@ust.edu.ph
} 
and instructs. The best stories are those whose sentences are beautifully weaved by creative writers who have a facility of words and who inspire readers to read. Thus, it is fundamentally in and through language that readers acquaint themselves with the 'experience' in literature.

As an area of applied linguistics, stylistics serves as a method of textual interpretation in which "primacy of place is assigned to language" (Simpson, 2004, p. 2). For stylisticians, language forms, patterns, and levels (e.g., phonology, morphology, syntax, semantics) are an important index of a text's function. This link between form and function is crucial to the definition of stylistics. Linguistics, which is an effective tool for literary interpretation, proves itself to be indispensable for the understanding of the structure, and most importantly, the effects of literature; thus, linguistics profoundly adds to one's experience and appreciation of literature. According to Leech (2008), "Within stylistics, that is, linguistic and literary concerns are as inseparably associated as the two sides of a coin, or (in the context of linguistics) the formal and functional aspects of a textual study" (p. 3). Further, because stylistics is an empirical discipline, it serves as a platform for the probable contextual and pragmatic effect of meaning(s) obtained from words in a selection, "testing ideas against texts and even generating ideas through textual interrogation" (Hall, 2014, p. 239).

The literature is rich in terms of stylistic analyses of fiction, particularly novels and short stories. Recent investigations have dealt with narrative and schematic structures of short stories (McCabe \& Bliss, 2003; Wong \& Lim, 2014), narratorial shift (Pakri \& Openg, 2014), narrative point of view (Tismo, 2008), narrative and discourse strategies (Ufot, 2014), text fragmentation as a foregrounding device (Emmott et al., 2006), speech and thought representation (Lintao, 2013), and character delineation through transitivity analysis (Salayo \& Lontoc-Macam, 2019). Interestingly, most stylistic studies on fiction dealt with linguistic and stylistic features on various aspects: corpus stylistics on comparing the language of fiction and oral narratives (Terblanche, 2016), on the pragmatics of $u$ h and $u m$ in a novel (Jucker, 2015a, 2015 b), and on the density and variety of parallelism used by an author in a novel (Zhao, 2012); connotation of adjectives (Elnaili, 2013; Weber, 2000, as cited in Carter \& Stockwell, 2008) and pronoun use as a foregrounding device (Levie \& Wildshut, 2014); modality based on points of view (Pariña \& De Leon, 2014); and translation as convergence or divergence of stylistic features (Tezcan, 2014; Ul, 2014).

While there has been a sustained interest in conducting stylistic studies on fiction, specifically novels and short stories, only a small number of these studies dealt with stories in English written by
Filipinos. Also, apart from the studies of Tarrayo (2017, 2018a, 2018b, 2019), the literature about stylistic analysis of flash fiction (FF) as a literary genre remains scant. In fact, the $21^{\text {st }}$ century has witnessed the gradual (yet slowly gaining) popularization of flash fiction in the Philippines. Anthologies either written in Filipino or in English of this genre were recently published such as Ang Autobiografia ng Ibang Lady Gaga by Jack Alvarez (2015), and Fast Food Fiction Delivery: Short Short Stories to Go edited by Noelle Q. de Jesus and Mookie Katigbak-Lacuesta (2015), which features 68 stories by 68 authors.

Taking off from previously done stylistic studies on fiction, which primarily focused on novels and short stories as major literary genres, this study endeavors to conduct a stylistic investigation of the very short story genre called flash fiction, which has been receiving considerable attention in the digital age. Although FF is a short form of narrative that may be told in less than 700 or 100 words, it is assumed to have the essential story details and stylistic and structural features compatible with its brevity (Ben-Porat, 2011; Guimarães, 2010; Nelles, 2012; Taha, 2000). Specifically, the present study attempts to conduct a lexical and syntactic analysis of Ian Rosales Casocot's "There Are Other Things Beside Brightness And Light."

\section{METHOD \\ Focus of analysis}

The present study provided an integrative, bottomup stylistic analysis of the FF under study. The analysis was anchored in two of the four linguistic and stylistic categories proposed by Leech and Short (2007), namely lexical and grammatical, since the focus of the study was on the lexical and syntactic aspects (the other two categories are on figures of speech, and context and cohesion). The questions in the list provided in Leech and Short's schema were discriminately adapted to suit the needs of the present study; thus, questions, which were found irrelevant were dispensed with, and only the useful ones were applied.

More so, the researcher went over and scoured the entirety of the text to examine the pattern of choices the writer had made. This pattern was composed of specific features that showed 'consistency' and 'tendency,' which could serve as empirical data in describing the writer's style. According to Leech and Short (2007), "'consistency' and 'tendency' are most naturally reduced to 'frequency', and so, it appears, the stylistician becomes a statistician" (p. 34). In other words, the researcher, at times, was tasked to note down the frequency of occurrence of discernible or noticeable linguistic features. Essentially, according to Leech and Short (2007), every stylistic analysis 
involves the selection of some features, and ignoring others; thus, it is a selective exercise, which may focus on one feature or several features. The quantitative linguistic proofs can serve as concrete evidence to support the intuitions the researcher may have about the FF piece. It should be recalled and noted, however, that an infrequent occurrence can likewise be a style marker; for instance, foregrounding, which can be a case of deviation (internal, grammatical, and the like) and is a basic principle in stylistic analysis, does not work solely on the basis of frequency.

\section{The flash fiction}

The FF "There Are Other Things Beside Brightness And Light" was selected among the 68 FF pieces in the anthology Fast Food Fiction Delivery: Short Short Stories to Go because it was written by Ian Rosales Casocot, whose exemplary contributions to fiction in English in the Philippines have been remarkable. Casocot teaches film, literature, and creative writing in Silliman University in Dumaguete City, the Philippines. This premier university offers academic programs in creative writing and organizes the annual Silliman University National Writers Workshop (SUNWW, established in 1962), which is the longest-running creative-writing workshop in Asia. Casocot has won several Palanca awards (the most prestigious literary-award-giving body in the Philippines) and the Fullybooked/Neil Gaiman Philippine Graphic/Fiction Prize for his fiction. The anthology, where the FF piece under study was taken, was published in the Philippines by Anvil Publishing, Inc. in 2015 and became a finalist in the $35^{\text {th }}$ National Book Awards for the category Best Anthology in English in 2016.

In the story, the narrator recalls the first time he ever felt pain when he was a nine-year-old boy, after witnessing how his father shot his [the boy's] Pomeranian in a boring drunken episode.

\section{FINDINGS AND DISCUSSION}

This section presents the findings based on the stylistic analysis of the FF piece in terms of lexical and grammatical categories. It should be noted that the (sub)categories used for the analysis were based upon Leech and Short's (2007) schema. Such a model provides a comprehensive list of questions as a guide for doing stylistic analysis of fiction (cf. Leech \& Short, 2007, pp. 61-66).

\section{Lexical categories \\ General}

The traumatic experience of the narrator is vividly depicted through the noticeable use of words that evoke sensations. These recollected sensations bring him back to that moment he first experienced pain. To prove this, the following examples taken from the story are herein cited.

\author{
Visual: $\quad$... my father shot Tibby with his gun. \\ ... which barely contained his swollen gut. \\ ... When father stared at me, as if to taunt \\ me, I held his eyes. \\ ... shaded by a hollowed out acacia tree in \\ the dark subdivision \\ ... Tibby's shattered head heaped upon my \\ father's decapitated body, blood dripping \\ down its jaws and into the soiled beer- \\ stained wifebeater my father wore that \\ night ... \\ ... a gathering blob of pure vacuum ... \\ And all I will ever learn to see from then on \\ is the dark side to everything.
}

Auditory: ... the dog barked too loudly ...

My father snorted ...

He guffawed.

Pain throbbed like an ancient truth ...

$\ldots$ the sound of a dog yelping, in that

frightened drawn-out cadence that signals knowledge of pain.

... white noise of nothingness ...

Smell: $\quad$ His breath reeked of beer.

Hell, I quickly knew, stank like this.

Touch/Feeling: ... spill his beer on his wifebeaters ...

... ending as a strange tingling between my legs that surprised me ...

All I could see in the feverish, quiet anger that swelled in my imagination ...

... I had a hard-on.

Through these words that evoke sensations, the narrator relates the traumatic experience that eventually made him practice detaching himself from everything and see the dark side to everything. The last sentence of the story, which emphasizes an explicit visual detail, can prove this interpretation: "And all I will ever learn to see from then on is the dark side to everything." It can be inferred from this that he has ignored feelings of compassion and drowned it all out with pessimism. He has learned to come to grips with the tragic experience, realizing that he should restrict himself from being attached to the things he values, for the end of such affairs is always pain, leaving him incomplete, shattered, and defeated.

The FF, moreover, predominantly employs words that evoke visual sensations. In keeping with this linguistic observation is the use of visual details in the title, which sounds dark, sad, and disturbing: "There Are Other Things Beside Brightness And Light." In addition, the visual description of the dark, cold place where the dog was buried makes death even sadder because the place itself is dead:

(1) After mother buried the animal in the backyard near the garbage cans, which were shaded by a hollowed out acacia tree in the dark subdivision where we lived, I finally mustered courage to ask father: "Why did you kill the dog?" 
The use of visual details also allows readers to undergo the same experience or feeling the narrator is having. The readers not only share the words that come to the character's mind but also the images that he creates in his inner world. Note how these words that evoke visual sensations let the readers feel the narrator's anger as he fantasizes about his father's death in this extract:

(2) All I could see in the feverish, quiet anger that swelled in my imagination was Tibby's shattered head heaped upon my father's decapitated body, blood dripping down its jaws and into the soiled beer-stained wifebeater my father wore that night - five years, eight months, and thirteen days before he died.

The use of words or expressions evoking sensations has been similarly observed in Cañares's (2002) and Tarrayo's (2017, 2018a) stylistic analyses of stream-of-consciousness short stories and FF pieces, respectively. Such words or expressions may be assumed as authors' attempt to paint a mental picture in the minds of readers. In fact, as a "visual thing . . . flash fiction needs to ignite the senses quickly and compellingly" (Hooks, 2017, para. 3). Likewise, to engage the readers in a response, carefully chosen words are brought to the forefront of an FF's visual palette.

Moreover, the story takes off with a maxim from The Aenid by Virgil, a Latin expression, "Sunt lacrimae rerum et mentem mortalia tangun, which translates to "There are tears in things and mortal things touch the mind." Strikingly, it captures the overall meaning of the story; that is, pain is inevitable as much as any other feelings-love, hate, jealousy, and sadness - in life or in mortal things. But for the poor child, the narrator, pain is everything. The Latin expression likewise resounds the controlling notions of detachment and attachment, and memory throughout the narrative. Further, the said Latin quote, the opening statement (i.e., "Detachment takes practice."), and descriptions such as "... Pain throbbed like an ancient truth..." and "... a gathering blob of pure vacuum that settles in my head and sits in it like a strange dark dream..." create the impression of a scholarly, learned narrator. Yet one unusual expression, i.e., "... fucking hard-on...," is rather too casual or colloquial for a sophisticated narrator. This sort of inconsistent language use could be an outlet for the narrator to strongly describe his anger and hatred as he recalls an early, impressionable, and extremely hurtful experience. His scholarly language could be his controlled side, while the dirty language seems to be his rough, uncouth side that sometimes finds release, especially when he recalls the trauma.

On the other hand, two slang words, i.e., wifebeater/s and hard-on, are essential to draw literary insights from the text. The word wifebeater is slang for a sleeveless shirt; its reputation comes from those wearing such shirts while engaged in domestic violence. This visual detail adds to the drama in the story as readers imagine the violent, macho, scary and 'wife-beater' image of the father. On the other hand, the word hard-on, which means an erection, is another important sensorial detail. Based on how the narrator describes the pain and anger he feels, such a physiological response could be a symbolic manifestation of his capacity to release anger.

\section{Nouns}

A majority of the nouns found in the story are concrete (36 or $60 \%$; see Table 1). Similar to findings of previous studies (Cañares, 2002; Tarrayo, 2017, 2018a), the predominant use of concrete nouns generally carries an important part of the meaning of a story. The description of the traumatic experience of the narrator is direct and concrete, leaving an impression of accessibility to the feelings of the main character.

Table 1

Abstract Nouns and Concrete Nouns Found in "There Are Other Things Beside Brightness And Light"

\begin{tabular}{|c|c|c|}
\hline \multirow{2}{*}{$\frac{\text { Abstract }}{\text { detachmeı }}$} & \multicolumn{2}{|l|}{ Concrete } \\
\hline & $\operatorname{dog}(s)^{*}$ & hard-on* \\
\hline practice & Pomeranian & night \\
\hline soul & brilliance (of hair) & sound \\
\hline world & hair & cadence \\
\hline cuteness & adults & noise \\
\hline devotion & children & blob \\
\hline episode & eyes* & \\
\hline courage & boy & \\
\hline rage & mass (i.e., dog) & \\
\hline time & foot & \\
\hline pain* & bed & \\
\hline truth & gun & \\
\hline moment & father* & \\
\hline insignificance & beer* & \\
\hline anger & wifebeater(s)* & \\
\hline imagination* & gut* & \\
\hline years & tingling & \\
\hline months & mother* & \\
\hline days* & animal & \\
\hline knowledge & backyard & \\
\hline (white noise of) & garbage cans & \\
\hline nothingness & & \\
\hline vacuum & acacia tree & \\
\hline dream & subdivision & \\
\hline side & body* & \\
\hline & fore & \\
\hline & legs & \\
\hline & mouse & \\
\hline & head* & \\
\hline & blood & \\
\hline & jaws & \\
\hline $\mathrm{F}=24(40 \%)$ & $\mathrm{F}=36(60 \%)$ & \\
\hline
\end{tabular}

For example, in the early part of the story, the description seems vivid that one can imagine the cute dog and how the narrator, as a child, took care 
of it. The use of several concrete nouns would also signify that although the killing happened years ago, all the sordid details of the event are still fresh in his memory. The following extract relating the said traumatic episode can prove this interpretation:

(3) I once cared about a dog named Tibby. It was a white Pomeranian - one of those frivolous types of dogs that are easy to love. The busy brilliance of their thick hair reduces even adults to squealing children. Tibby - if I try to recall correctly-was a gentle soul. He had eyes that seemed to see through me. I was a young boy, and he was my world - a yapping mass of cuteness that required devotion. I fed him, I bathed him. Tibby slept at the foot of my bed. Once, in a boring drunken episode, my father shot Tibby with his gun. He said the dog barked too loudly, it made him spill his beer on his wifebeaters, which barely contained his swollen gut.

As revealed in recent stylistic studies (Tarrayo, 2017, 2018a), abstract nouns also lend themselves well in reinforcing significant details in FF. More so, these nouns, either concrete or abstract, can be grouped based on specific semantic fields to convey literary insights. In the present study, one group of abstract nouns refers to psychological or emotional processes: detachment, devotion, courage, rage, pain, anger, imagination, knowledge, nothingness, and dream. These words would emphasize how the narrator struggled to detach himself from the memory of Tibby and from the memory of the trauma his father caused him. As a result, he consumed himself with pessimism and ignored feelings of compassion. This sort of abstraction is made evident in the last paragraph of the text:

(4) Later on, in my quiet days, my imagination tries to spring on me the sound of a dog yelping, in that frightened drawn-out cadence that signals knowledge of pain. But I have learned to drown that out with the white noise of nothingness - a gathering blob of pure vacuum that settles in my head and sits in it like a strange dark dream. And all I will ever learn to see from then on is the dark side to everything.

Only one proper noun or name is used in the narrative, i.e., Tibby, the Pomeranian dog, yet it is essential to emphasize the strong attachment of the narrator to the dog. In most instances, when people give something a name, it creates a bond with them, showing that it is their possession and that they value it. This sort of attachment made the narrator feel hurt and devastated upon painfully witnessing how his father brutally killed Tibby.

\section{Adjectives}

To accompany the predominant use of concrete nouns to depict the recollected sensations of the narrator, the adjectives in the story bring sensory imageries, particularly visual (11): white, busy (brilliance), thick, swollen, hollowed out (acacia tree), dark, little, shattered, decapitated, soiled, and beer-stained. The words white and busy (brilliance) contrast vividly with hollowed out (acacia tree), dark, soiled, and beer-stained, bringing small signs of brightness and light against the dark and blighted background. Another group of adjectives refers to psychological states (13): frivolous, easy (to love), gentle, boring drunken (episode), angrier, feverish, quiet (anger), fucking (hard-on), quiet (days), frightened, strange (dream), dark (dream), dark (side). Most of these adjectives carry negative connotations, underscoring the traumatic episode in the narrator's life that made an impact on how he sees things; that is, at such a young age, he learned of the cruelty of things around him - the other things beside brightness and light.

Adjectives create strong impressions that enable readers to undergo vicariously the experiences of characters in FF. According to Lombardi (2003), sensory experience "lures readers into the fictional world" and the use of specific sensory details leads to verisimilitude - the sense that story events really happened (p. 107). In the FF under study, the use of adjectives that entail psychological states would emphasize that the narrator's memory of his special attachment to his dog, which was his brightness and light, has been overshadowed by the cruelty and darkness in his household.

\section{Verbs}

Stative and dynamic verbs are frequently employed in the narrative (12 and 16, respectively). These same fundamental textual features have been found significant in previous studies (Cañares, 2002; Tarrayo, 2017, 2018a). Examples of stative verbs that have implications of movement, indicating physical position or posture (Leech \& Short, 2007) include: slept, contained, held, (could not be) moved, buried, shaded, lived, swelled, wore, died, settles, and sits. Examples of dynamic verbs include reduces, fed, bathed, shot, spill, kill, and signals. Some of the dynamic verbs likewise refer to sense perceptions such as see, barked, stared, and snorted. The frequent use of stative verbs vis-à-vis the equally noticeable set of dynamic verbs serves to echo the impressions of attachment and detachment, and memory in the story. Adding to this effect is the set of verbs denoting psychological states or activities (12): takes (practice), cared about (a dog), recall (Tibby), required (devotion), dammed (whatever it was that threatened to overwhelm), threatened, guffawed, had (ever) felt (pain), surprised, (imagination) tries, have learned, and will learn. The narrator's memory of his special attachment to the dog, which was his brightness and light, has been overshadowed by the unkindness and darkness of things in his household, narrowing his focus on the negatives of his life and learning to see "the dark side to everything." 
Actions are essential in FF because they convey to the readers the tension between what is said and unsaid; most importantly, these actions create momentum and, at the same time, reveal character. Leslie (2009) claims that in FF, the “'action,' so to speak, is entirely internal, beneath the surface, intimate" (p. 9).

\section{Adverbs}

The narrative only contains four adverbs of manner that contribute to the literary interpretations of the text. The following extracts show the use of these adverbs:

(5) Tibby - if I try to recall correctly — was a gentle soul.

(6) He said the dog barked too loudly, it made him spill his beer on his wifebeaters, which barely contained his swollen gut.

(7) Hell, I quickly knew, stank like this.

It can be inferred from Extract 5 that the narrator is still trying his best to detach himself from the memory of Tibby; note the expression "if I try to recall correctly." The use of the manner adverbs in Extract 6, on the other hand, puts emphasis on the image of the father as a drunkard and a short fuse who lost his patience over a yapping hyperactive dog. In Extract 7, one can feel the extreme hatred of the narrator toward his father; he sees his father as a demon, as he associates his father's breath to the stench of hell.

\section{Grammatical categories \\ Sentence complexity}

The noticeable use of cumulative or loose sentences helps depict a series of rapid thoughts as the narrator recalls a traumatic experience and tells the story, with a reminiscent voice, about his dog named Tibby. This linguistic observation is consistent with findings from recent studies on FF (Tarrayo, 2017, 2018a), which revealed that the use of cumulative or loose sentences helps build and intensify tension in FF. Three sentences in the second paragraph of the text illustrate the use of cumulative sentences in which the main clause(s) is elaborated by subordinate or modifying elements:

(8) I once cared about a dog named Tibby. It was a white Pomeranian-one of those frivolous types of dogs that are easy to love. The busy brilliance of their thick hair reduces even adults to squealing children. Tibby-if I try to recall correctly - was a gentle soul. He had eyes that seemed to see through me. I was a young boy, and he was my world - a yapping mass of cuteness that required devotion. I fed him, I bathed him. Tibby slept at the foot of my bed. Once, in a boring drunken episode, my father shot Tibby with his gun. He said the dog barked too loudly, it made him spill his beer on his wifebeaters, which barely contained his swollen gut.
After naming the dog, the narrator went on by describing Tibby from its most generic attributes all the way to its intrinsic qualities. A white and fluffy Pomeranian, Tibby is presented as a pure and lovable dog. However, what is noticeable here is the use of an em dash (-) after a generic attribute. It is as if the narrator is going beyond the physical description of Tibby as a white Pomeranian with its thick hair and embarks on a trip down memory lane as how Tibby was to him as a nine-year-old boy. It is evident that Tibby was the narrator's refuge: "He had eyes that seemed to see through me. I was a young boy, and he was my world-a yapping mass of cuteness that required devotion." There is a special attachment between him and the dog-an attachment that he did not find anywhere else, even in his household. His father, being the antagonist, ended this attachment with a gunshot aimed at the dog.

Another set of sentences in the narrative show the use of cumulative sentences to convey the central notions of attachment and detachment, and memory (see Extracts 9 and 10 below). Such embedding in these sentences makes the readers suspect that they are no longer inside the consciousness of the boy narrator; rather, it is now the mature narrator taking over. As evidenced by the use of these sentences, the narrator vividly and spontaneously recollects the painful experience that made him realize that truly, there are other things beside brightness and light; and for him, it is darkness.

(9) Pain throbbed like an ancient truth, coming to the fore from the gut, ending as a strange tingling between my legs that surprised me, just for a moment.

(10) There was pain, and there was father looking at me like I was a mouse, a small, talking insignificance.

(11) All I could see in the feverish, quiet anger that swelled in my imagination was Tibby's shattered head heaped upon my father's decapitated body, blood dripping down its jaws and into the soiled beer-stained wifebeater my father wore that night - five years, eight months, and thirteen days before he died.

(12) Later on, in my quiet days, my imagination tries to spring on me the sound of a dog yelping, in that frightened drawn-out cadence that signals knowledge of pain.

(13) But I have learned to drown that out with the white noise of nothingness - a gathering blob of pure vacuum that settles in my head and sits in it like a strange dark dream.

The cumulative sentence in Extract 11, for instance, shows that the narrator was so hurt that he wished his father dead. Unprompted, he had been counting the days and had fantasies about it.

On the other hand, two short sentences in the narrative resemble what Emmott et al. (2006) called 'mini-paragraphs':

(14) Detachment takes practice. 


\section{(15) He guffawed.}

Because of its brevity, the use of a miniparagraph as a text fragmentation serves as a foregrounding device in narratives to underscore significant information; depending on context, a sentence fragment helps convey a special or dramatic emphasis in a story (Emmott et al., 2006). Extract 14, which is the first sentence-paragraph of the FF, seems explicit or straightforward to suggest the theme of the story; notice, too, that it is in itself detached from the rest of the work. The second mini-paragraph (i.e., Extract 15) emphasizes how the father looks down upon the narrator; the act of laughing taunts the narrator, making him feel he is insignificant. How a man [the father] can be so powerful as to take a life, yet he [the narrator] is powerless to do anything about it. The shortness of this one-sentence paragraph would allow the readers to feel more strongly the monstrosity of the father; the kind of laugh (a guffaw is uncouth) and the very absence of details highlight the callousness of the father.

\section{Verb tenses}

Predominantly used in FF is the past tense, which serves a specific stylistic purpose. The past tense conveys a more reflective nature of the story as the narrator recalls a traumatic episode in his life and retells the story events to the readers. The use of the past tense highlights that the story happened from a distant past and that the narrator wants to keep all the bad memories in the past. By keeping the past tense glaring, the narrator stresses that he has changed and is no longer the weak and sniveling nine-year-old boy. His reflective voice carries his stance now in relation to the experience he had then. It can be inferred from the first sentence of paragraph 9 (i.e., "I remember that was the first time I'd ever felt pain.") that he is looking back now to that painful experience when he was nine. The said statement then is followed by a vivid recollection of the event.

At a closer look, however, one may notice the use of the present and the future tenses in the last paragraph:

(16) Later on, in my quiet days, my imagination tries to spring on me the sound of a dog yelping, in that frightened drawn-out cadence that signals knowledge of pain. But I have learned to drown that out with the white noise of nothingness - a gathering blob of pure vacuum that settles in my head and sits in it like a strange dark dream. And all I will ever learn to see from then on is the dark side to everything.

In this last part of the text, the narrator acknowledges the past that will undeniably affect much of the future. Simply put, it tells the readers that for the narrator, there is no getting away from the sad reality and the cruelty of things around him. This technique of switching between verb tenses seems to lure readers more strongly into the suspense of stories, capturing the thrill, texture, and flux of events (Cañares, 2002; Tarrayo, 2018a).

\section{Demonstrative pronouns}

Leech and Short's (2007) schema likewise points out the possible stylistic effect on literary interpretation of minor word classes or 'function words' that include prepositions, conjunctions, pronouns, determiners, auxiliaries, and interjections. For instance, Levie and Wildshut's (2014) study has revealed that pronouns can be used as a foregrounding device in a story. In the FF analyzed, the demonstrative pronouns that and this in these two sentences from paragraph 9 create a particular effect: "I remember that was the first time I'd ever felt pain. Perhaps this was also the last." First, the narrator used that, which refers to something distant, but in the next sentence, he used this, which pertains to something near or close. Both pronouns pertain to the moment the narrator felt devastated upon experiencing the cruelty of the father - the "first time" he "ever felt pain." The use of that and this in the said juxtaposed sentences tends to reinforce the struggle or difficulty of the narrator to detach himself or to escape from the vexatious memory of this pain (Notice the words I remember.).

\section{Punctuation}

Notably, the FF exhibits a taste for em dash (-). Throughout the narrative, six em dashes are found. In common use, an em dash functions like a pair of parentheses, which in effect encloses a word, a phrase, or a clause in a sentence. As a result, an idea may be amplified by means of enclosing it within a pair of em dashes. This amplification through the use of em dash may also signify the attempt on the part of the narrator to access his memory to draw out details and recollection relative to what he is talking about. In the story, what is noteworthy is that the em dash paves the way for a forthcoming emotional rumination. It augments and concretizes details that are indeed material to the overall effect of the narrative.

The following sentences culled from the FF are analyzed to illustrate the significance of the em dash in revealing meaningful literary interpretations:

(17) I once cared about a dog named Tibby. It was a white Pomeranian - one of those frivolous types of dogs that are easy to love.

(18) Tibby — if I try to recall correctly — was a gentle soul.

(19) He had eyes that seemed to see through me. I was a young boy, and he was my world-a yapping mass of cuteness that required devotion.

(20) All I could see in the feverish, quiet anger that swelled in my imagination was Tibby's shattered head heaped upon my father's decapitated body, blood dripping down its jaws 
and into the soiled beer-stained wifebeater my father wore that night-five years, eight months, and thirteen days before he died.

(21) But I have learned to drown that out with the white noise of nothingness - a gathering blob of pure vacuum that settles in my head and sits in it like a strange dark dream.

The first statement in the above extracts (i.e., Extract 17) has a single em dash that separates the noun 'Pomeranian' from the phrase that acts as an appositive explaining it further. The explanation seems to be an afterthought on the part of the narrator; thus, the em dash connotes a pause made before the explanation is given. Notice that the explaining or amplifying detail just gives the generic attributes of Pomeranian as a dog breed.

Usually, a pair of em dashes sets off from the rest of the sentence expressions that merely supply additional information and are, therefore, not essential to the meaning the sentence conveys. While this assumption holds water in most instances, the em dash in Extract 18, on the other hand, performs a different function. The expression enclosed by a pair of em dashes can be dispensed with and what remain can stand on their own. However, as a stylistic device, the use of this pair of em dashes in the said extract triggers a sudden break in thought of the narrator, showing his hesitation as he tries his best to detach himself from the memory of Tibby. After that statement, the narrator continued describing more intricate and 'personal' qualities of Tibby. The use of an em dash in Extract 19 can prove this, as one would decipher the emphasis given by the said punctuation to add poignancy to the clause "... he was my world..."

Further, the em dash employed in Extract 20 inherently carries so much tension as the narrator imagines or fantasizes about the death of his father. Adding to this effect is the intensely emotive scene ender indicated by the em dash in Extract 21; that is, the narrator decides to detach himself from everything.

The em dash is employed to show the piling up of ideas, memories, and sensations in the mind of characters and narrators (Cañares, 2002; Tarrayo, 2017, 2018a). In the FF analyzed, it represents the emotional rumination of the first-person narrator who straddles between his memory and attachment, and detachment with his dog Tibby.

\section{CONCLUSION}

The present study, in the purview of stylistics, endeavored to conduct a lexical and syntactic analysis of one FF, an area in the literature which has not been given enough attention by scholars. The stylistic investigation of the FF may prove that the art of brevity means the art of processing as much as the art of expression.
While the FF is inherently brief, it gives much more details about the traumatic experience of the narrator. A detailed lexical and syntactic analysis of the FF elucidates this idea the writer wants to evoke. To communicate such an experience, it was found that the writer used words that evoke the main character's recollected sensations, particularly visual; a Latin expression; and slang words. Adding to this effect is the use of more concrete nouns, which leave an impression of accessibility to the feelings of the main character, some abstract nouns that connote psychological or emotional processes, and one (the only) proper noun, i.e., Tibby, the Pomeranian dog. Accompanying these concrete and abstract nouns are adjectives that bring sensory imageries and represent, along with some verbs, psychological states, which carry negative connotations. The frequent use of stative verbs visà-vis the equally noticeable set of dynamic verbs serves to echo the impressions of attachment and detachment, and memory in the story, which can also be linked to the identified adverbs of manner in the text.

With respect to the syntactic analysis of the $\mathrm{FF}$, it was found that the use of cumulative or loose sentences helps depict a series of rapid thoughts as the narrator recalls a traumatic experience and tells the story. Likewise, the use of mini-paragraphs as forms of text fragmentation helps foreground the theme of the narrative. Reinforcing the struggle or difficulty of the narrator to detach himself or to escape from the vexatious memory of pain and trauma are the verb-tense shift from past to future, and the use of demonstrative pronouns that and this. Noticeable, too, is the frequent use of the em dash, which paves the way for the narrator's emotional rumination.

The stylistic analysis, particularly lexical and syntactic, provides a more objective and profound understanding of the underlying meanings of the FF under study. Through the analysis, it can be argued that FF's length restrictions can bring out great art. Since the genre's form demands economy, attention to its ambiguous, subtle, and secretive, so to speak, language is necessary. In a small and tight space, FF's language is essentially associative to capture (and capture well) and dramatize an experience and evoke emotions; in an artistic way, the power of its language communicates something different, for a good FF should "catch you as you turn away, hold you, and when you've finished reading, it should echo and resonate" (Gebbie, 2009, p. 54).

\section{REFERENCES}

Alvarez, J. (2015). Ang autobiografia ng ibang Lady Gaga. Visprint, Inc.

Ben-Porat, Z. (2011). From flash fiction to nanoliterature or what can be learned from 6 word long micro-stories [Paper presentation]. The 
Atas do Simpósio Internacional "Microcontos e outras microformas". Centro de Estudos Humanísticos. Universidade do Minho, Braga, Portugal.

Cañares, M. F. (2002). Five stream-ofconsciousness short stories: A stylistic investigation (Unpublished doctoral dissertation). Philippine Normal University.

Carter, R., \& Stockwell, P. (Eds.). (2008). The language and literature reader. Routledge.

De Jesus, N. Q., \& Katigbak-Lacuesta, M. (Eds.). (2015). Fast food fiction delivery: Short short stories to go. Anvil Publishing, Inc.

Elnaili, S. (2013). A stylistic analysis of libyan short stories: The connotation of adjectives [Unpublished master's thesis]. Louisiana State University.

Emmott, C., Sanford, A. J., \& Morrow, L. I. (2006). Capturing the attention of readers? Stylistic and psychological perspectives on the use and effect of text fragmentation in narratives. Journal of Literary Semantics, 35, 1-30. https://doi.org/10.1515/JLS.2006.001

Gebbie, V. (2009). Fireworks and burnt toast: The process of opening up your writing. In T.L. Masih (Ed.), The Rose Metal Press field guide to writing flash fiction (pp. 54-64). Rose Metal Press.

Guimarães, J.F.N. (2010). The short-short story: A new literary genre [Upublished master's thesis]. Universidade Federal de Minas Gerais.

Hall, G. (2014). Pedagogical stylistics. In M. Burke (Ed.), The Routledge handbook of stylistics (pp. 239-252). Routledge.

Hooks, S. (2017). Protean miniatures: The adaptability and sustainability of flash fiction. https://lareviewofbooks.org/article/proteanminiatures-adaptability-sustainability-flashfiction/\#

Jucker, A. H. (2015a). Uh and um as planners in the Corpus of Historical American English. In T. Irma, K. Merja, C. Claudia, \& S. Jeremy (Eds.), Developments in English: Expanding electronic evidence (pp. 162-177). Cambridge University Press.

Jucker, A. H. (2015b). Pragmatics of fiction: Literary uses of uh and um. Journal of Pragmatics, 86, 63-67. https://doi.org/10.1016/j.pragma.2015.05.012

Leech, G. (2008). Language in literature. Pearson Education Limited.

Leech, G., \& Short, M. (2007). Style in fiction: A linguistic introduction to English fictional prose ( $2^{\text {nd }}$ ed.). Pearson Education Limited.

Leslie, N. (2009). That "V" word. In T.L. Masih (Ed.), The Rose Metal Press field guide to writing flash fiction (pp. 7-14). Rose Metal Press.

Levie, S., \& Wildschut, P. (2014). Narrating the unspeakable. Person marking and focalization in Nabokov's short story "Signs and Symbols". Journal of Literary Semantics, 43(2), 87-108. https://doi.org/10.1515/jls-2014-0007

Lintao, R. B. (2013). Traversing the speech and thought presentation features of Merlinda Bobis's “The Sadness Collector". Asian Journal of English Language Studies, 1, 35-60. https://ajels.ust.edu.ph/wpcontent/uploads/2018/09/3-Traversing-thespeech-and-thought-presentation-features-ofMerlinda-Bobis\%E2\%80\%99s$\%$ E2\%80\%9CThe-SadnessCollector\%E2\%80\%9D.pdf

Lombardi, C. (2003). Description: To picture in words. In A. Steele, Writing fiction: The practical guide from New York's acclaimed creative writing school (pp. 104-125). Bloomsbury.

McCabe, A., \& Bliss, L. S. (2003). Patterns of narrative discourse: A multicultural, life span approach. Pearson Education Limited.

Nelles, W. (2012). Microfiction: What makes a very short story very short? Narrative, 20(1), 87104. https://doi.org/10.1353/nar.2012.0002

Pakri, M. R., \& Openg, E. J. (2014). A stylistic analysis of a selected short story in Agnes Newton Keith's 'Land below the Wind': Narratorial shift, ambivalence and mimicry in colonial writing. Procedia - Social and Behavioral Sciences, 134, 161-165. https://doi.org/10.1016/j.sbspro.2014.04.235

Pariña, J. C. M., \& de Leon, K. D. (2014). A stylistic analysis of the use of modality to identify the point of view in a short story. $3 L$ : The Southeast Asian Journal of English Language Studies, 20(2), 91-100. http://dx.doi.org/10.17576/3L-2014-2002-08

Salayo, J. D., \& Lontoc-Macam, A. (2019). Exploring character delineation: A transitivity analysis of O. Henry's “A Retrieved Reformation”. Asian Journal of English Language Studies, 7, 151-168. https://ajels.ust.edu.ph/wpcontent/uploads/2019/11/7_Exploringcharacter-delineation_A-transitivity-analysisof-O.-Henrys-A-Retrieved-Reformation.pdf

Simpson, P. (2004). Stylistics: A resource book for students. Routledge.

Taha, I. (2000). The modern Arabic very short story: A generic approach. Journal of Arabic Literature, 31(1), 59-84. https://doi.org/10.1163/157006400X00070

Tarrayo, V. N. (2017). Capturing the language of flash fiction: A stylistic analysis of a Filipinoauthored "short" short story. Philippine Journal of Linguistics, 48, 51-74.

Tarrayo, V. N. (2018a). Exploring the coalescence of language and literature through a stylistic analysis of Cristina Pantoja Hidalgo's "When It's A Grey November In Your Soul”. $i$ - 
manager's Journal on English Language

Teaching, 8(1), 1-17.

https://doi.org/10.26634/jelt.8.1.13944

Tarrayo, V. N. (2018b). Beauty in brevity:

Capturing the narrative structure of flash

fiction by Filipino writers. $i$-manager's

Journal on English Language Teaching, 8(2), 36-56. https://doi.org/10.26634/jelt.8.2.14584

Tarrayo, V. N. (2019). What's in a flash? Teaching reading and writing (and beyond) through flash fiction. English Language Teaching and Research Journal, 1(1), 9-15. https://doi.org/10.33474/eltar-j.v1i1.4773

Terblanche, L. (2016). The language of stories: Modelling East African fiction and oral narratives. Southern African Linguistics and Applied Language Studies, 34(1), 27-41. https://doi.org/10.2989/16073614.2015.113199 1

Tezcan, T. (2014). A stylistic analysis of 'A Rose for Emily' by William Faulkner and its Turkish translation. Procedia - Social and Behavioral Sciences, 158, 364-369. https://doi.org/10.1016/j.sbspro.2014.12.101
Tismo, B. S. (2008). Point of view in six Matsumoto stories: A stylistic analysis. Kinaadman, $X X X$, 23-66.

Ufot, B. (2014). Narrative stylistics: A study of the narrative and discourse strategies in Omotoso's Just Before Dawn. English Linguistics Research, 3(1), 28-38. https://doi.org/10.5430/elr.v3n1p28

Ul, B. (2014). Foregrounded: A comparative stylistic analysis of Their Eyes Were Watching God and its Turkish translation. ProcediaSocial and Behavioral Sciences, 158, 37-42. https://doi.org/10.1016/j.sbspro.2014.12.030

Wong, V., \& Lim, J. M. (2014). Linking communicative functions with linguistic resources in short stories: Implications of a narrative analysis for second language writing instruction. System, 45, 147-162. https://doi.org/10.1016/j.system.2014.05.008

Zhao, M. (2012). The art of balance: A corpusassisted stylistic analysis of Woolfian parallelism in To the Lighthouse. International Journal of English Studies, 12(2), 39-58. https://doi.org/10.6018/ijes/2012/2/161741 


\author{
Appendix \\ The flash fiction under study
}

\title{
There Are Other Things Beside Brightness And Light Ian Rosales Casocot
}

\author{
"Sunt lacrimae rerum et mentem mortalia tangun." \\ - Virgil, The Aenid
}

Detachment takes practice.

I once cared about a dog named Tibby. It was a white Pomeranian —one of those frivolous types of dogs that are easy to love. The busy brilliance of their thick hair reduces even adults to squealing children. Tibby - if I try to recall correctly — was a gentle soul. He had eyes that seemed to see through me. I was a young boy, and he was my world - a yapping mass of cuteness that required devotion. I fed him, I bathed him. Tibby slept at the foot of my bed. Once, in a boring drunken episode, my father shot Tibby with his gun. He said the dog barked too loudly, it made him spill his beer on his wifebeaters, which barely contained his swollen gut.

Mother told me not to cry. "It would make your father angrier," she said.

So I didn't cry. I dammed whatever it was that threatened to overwhelm. When father stared at me, as if to taunt me, I held his eyes. I could not be moved. I did not cry.

After mother buried the animal in the backyard near the garbage cans, which were shaded by a hollowed out acacia tree in the dark subdivision where we lived, I finally mustered courage to ask father: "Why did you kill the dog?"

He didn't seem to get that there was rage swelling in my little body. My father snorted, and then he said, "Because I could."

He guffawed.

His breath reeked of beer. Hell, I quickly knew, stank like this.

I remember that was the first time I'd ever felt pain. Perhaps this was also the last. I was nine. Pain throbbed like an ancient truth, coming to the fore from the gut, ending as a strange tingling between my legs that surprised me, just for a moment. There was pain, and there was father looking at me like I was a mouse, a small, talking insignificance. All I could see in the feverish, quiet anger that swelled in my imagination was Tibby's shattered head heaped upon my father's decapitated body, blood dripping down its jaws and into the soiled beerstained wifebeater my father wore that night - five years, eight months, and thirteen days before he died.

I had a hard-on. I remembered that most of all. At nine, I had a fucking hard-on.

Later on, in my quiet days, my imagination tries to spring on me the sound of a dog yelping, in that frightened drawn-out cadence that signals knowledge of pain. But I have learned to drown that out with the white noise of nothingness - a gathering blob of pure vacuum that settles in my head and sits in it like a strange dark dream. And all I will ever learn to see from then on is the dark side to everything.

(496 WORDS) 